\title{
Interactive comment on "Estimation of Hourly Land Surface Heat Fluxes over the Tibetan Plateau by the Combined Use of Geostationary and Polar Orbiting Satellites" by Lei Zhong et al.
}

Lei Zhong et al.

zhonglei@ustc.edu.cn

Received and published: 16 March 2019

The comment was uploaded in the form of a supplement:

https://www.atmos-chem-phys-discuss.net/acp-2018-1165/acp-2018-1165-AC3-

supplement.pdf

Interactive comment on Atmos. Chem. Phys. Discuss., https://doi.org/10.5194/acp-2018-1165, 2018. 